\title{
Tıp Fakültesi Dönem 1 ve Dönem 2 Öğrencilerinin Anatomi Pratik Eğitimini Değerlendirmeleri
}

\author{
Alper VATANSEVER, Emrah ÖZCAN
}

Balıkesir Üniversitesi Tıp Fakültesi, Anatomi Anabilim Dalı, Balıkesir.

\begin{abstract}
ÖZET
Çalışmamız, tıp fakültesi öğrencilerinin, anatomi pratik eğitimi sırasında karşılaştıkları zorlukların belirlenebilmesi ve çözümlenmesi ile birlikte anatomi pratik derslerinin daha etkili bir yönteme dönüştürülmesini amaçlamaktadır. Bu noktadan yola çıılarak, anatomi eğitimine yeni başlamış ve anatomi eğitimini bitirmek üzere olan toplam 226 öğrenci çalışmamıza dahil edilmiştir. Bu öğrencilere, açık uçlu ve çoktan seçmeli sorulardan oluşan 30 soruluk anket uygulaması yapılmıştır. Anket uygulaması tamamlandıktan sonra elde edilen yanıtlar, SPSS 21 paket programı ile değerlendirilmiştir. Çalışmamıza katılan öğrencilerden 225'i $(\% 99,6)$, anatomi dersinin işlenişi hakkında kendilerinin de fikirlerinin alınması gerektiğini belirtmişlerdir. Bunun yanında, anatomi eğitimi için vazgeçilmez olan kadavra gösteriminin yanı sıra, radyolojik görüntülerin de yardımcı eğitim aracı olarak kullanılması gerektiğini düşünmektedirler $(\% 72,6)$. Elde edilen bulgular, anatomi pratik eğitiminin daha etkili bir yöntemle ilerleyebilmesi için tıp fakültesi öğrencilerinin fikirlerinin alınmasının gerekliliğini ortaya koymaktadır.
\end{abstract}

Anahtar Kelimeler: Anatomi pratiği. Öğrenci geri bildirimi. Tip eğitimi.

Evaluation of Anatomy Practical Education by Phase 1 and Phase 2 Medical Students

\begin{abstract}
Aim of our study was detection of medical students' difficulties during anatomy practical education and creating more effective anatomy practical education by resolving their problems. For this purpose, a total of 226 medical students who had just started and were about to complete anatomy lectures were included. A questionnaire consisting of 30 questions including of open-ended and multiple choice questions was given to these students. After the questionnaire was completed, the responses were evaluated using the SPSS 21 software. 225 (99.6\%) of the students participating in this study stated that it was necessary to ask their ideas about the anatomy courses. Furthermore, besides the cadaver demonstration which is indispensable for anatomy education, radiological images should be used as an auxiliary educational tool (72.6\%). Our results revealed that it was necessary to ask the medical students' ideas for proceeding the anatomy practical courses with a more effective method.
\end{abstract}

Key Words: Anatomy practical course. Students' feedback. Medical education.

Ülkemizde ve tüm dünyada uygulanan tıp eğitimi, daha sağlıklı nesiller yetişmesi için ve toplumların gereksinimlerini karşılayabilecek donanımlı hekimler yetiştirmeyi hedeflemektedir ${ }^{1}$. Tıp eğitimi sırasında oldukça büyük bir öneme sahip olan anatomi bilimi, insan vücudunu, vücudu oluşturan sistemleri, sistemleri meydana getiren organları yapısal ve işlevsel olarak ve bu organların birbirleriyle olan ilişkilerini incelemektedir ${ }^{2}$. Tarihin en eski bilim dalı olan ana-

Geliş Tarihi: 31 Mayıs 2018

Kabul Tarihi: 16 Temmuz 2018

Dr. Alper VATANSEVER

Balıkesir Üniversitesi, Tıp Fakültesi,

Anatomi Anabilim Dalı, Çağış Kampüsü,

10145, Balıkesir

İrtibat Telefonu: 05383681312

E-posta Adresi: alpervatansever@yahoo.com tomi, geleneksel eğitim yöntemlerinin yanı sıra, günümüzde teknolojinin gelişmesi ve materyal çeşitliliğinin artması ile birlikte eğitim alanında çok farklı bir boyuta ulaşmıştır ${ }^{3,4}$.

Anatomi eğitiminin vazgeçilemez ve en etkili öğretim yöntemi kadavra diseksiyonudur. Günümüzde bununla birlikte, anatomik modeller, bilgisayar yazılımları ve eğitim videoları gibi yardımcı eğitim araçlarından da sıklıkla faydalanılmaktadır. Özellikle, son dönemlerde yaşanan kadavra teminindeki sıkıntılar sebebiyle yardımcı eğitim araçlarına yönelik ihtiyaç giderek artmaktadır. Öğrenci sayısının fazla olması, gerek amfi derslerinde ve gerekse laboratuvar uygulamalarında bir takım sıkıntılar ortaya koyabilmektedir. Ancak, laboratuvar uygulamaları sırasında, öğrencilerin daha küçük gruplara ayrılması ile birlikte daha etkili bir anatomi pratik eğitiminin yapılabilmesi mümkün hale gelebilmektedir. Tüm bunlara rağmen, öğrencilerin 


\section{A. Vatansever, ark.}

laboratuvar eğitimleri sırasında karşılaştıkları problemlerin başında, anatomik oluşumların 3 boyutlu olarak kavranabilmesi sırasındaki yaşadığı güçlükler gelmektedir ${ }^{5}$.

Tıp fakültesi öğrencilerinin, anatomi laboratuvar eğitim sırasında karşılaştıkları bu zorlukların daha kolay ve anlaşılır hale getirilmesi, daha kaliteli bir anatomi eğitimi açısından oldukça büyük bir öneme sahiptir. $\mathrm{Bu}$ noktadan yola çıkılarak çalışmamızın amacı, anatomi laboratuvar eğitimine yeni başlayan ve bu eğitimi tamamlamış öğrencilerin düşüncelerinin ve önerilerinin dinlenmesidir.

\section{Gereç ve Yöntem}

Çalışmamızda, Balıkesir Üniversitesi Tıp Fakültesi 2017 - 2018 eğitim-öğretim yılının bahar yarıyılında anatomi dersi almaya başlayan dönem 1 öğrencileri (n = 118) ve $2016-2017$ eğitim - öğretim yılının bahar yarıyılında anatomi dersi almaya başlamış ve 2017 2018 eğitim - öğretim yılında tüm anatomi derslerini tamamlayan dönem 2 öğrencileri $(\mathrm{n}=108)$ olmak üzere toplam 226 öğrenci dahil edilmiştir. Çalışmamıza katılan 125 erkek $(\% 55,3)$ ve 101 kadın $(\% 44,7)$ öğrencinin yaşları 18 ile 32 arasında olup ortalaması 20,08 $\pm 1,82$ 'dir. Çalışmaya dahil edilen öğrencilere, gerekli literatür taraması yapılarak anket soruları uygulanmıştır. Uygulanan anket, 3 adet açık uçlu ve 26 adet çoktan seçmeli sorudan oluşmaktadır. Yanıtların güvenilirliğini arttırmak ve öğrencilerin kendilerini bask1 altında hissetmemeleri amacıyla, öğrencilerden anket formlarına hiçbir kimlik bilgilerini yazmamaları istenmiştir.

Öğrencilerden toplanan yanıtların SPSS 21 paket programına kaydedilmesinin ardından istatistiksel analizler tamamlanmıştır. Verilen yanıtların yüzdelik dağılımlarını belirlemek amacıyla, frekans analizleri uygulanmıştır. Gruplar arasındaki karşılaştırmalar ve yanıtların birbirleriyle ve gruplar arasındaki ilişkilerinin ortaya konulabilmesi amaciyla uygun istatistiksel testler uygulanmıştır. Analizler sonucunda, $p$ değeri 0,05’ten küçük olan veriler, istatistiksel olarak anlamlı şeklinde yorumlanmıştır.

Çalışmamıza, Balıkesir Üniversitesi Tıp Fakültesi Girişimsel Olmayan Klinik Uygulamalar Etik Kurulu'nun 2018/115 sayılı onayı alındıktan sonra başlanmiştır.

\section{Bulgular}

Çalışmamıza dahil edilen öğrencilerin \%83,4'u Tıp Fakültesini kendi istekleri ile seçtiklerini belirtirken, geri kalan öğrenciler bu tercihin kendi istekleri olmadıklarını söylemişlerdir $(\% 16,6)$.
Öğrencilerin \%99,6's1, anatomi pratik derslerinin değerlendirilmesi konusunda kendilerinin fikirlerinin sorulmasının gerekli olduğunu belirtmiştir.

Şekil 1'de öğrencilerin, anatomi pratik derslerinin hangi saatte başlamasını istedikleri özetlenmektedir.

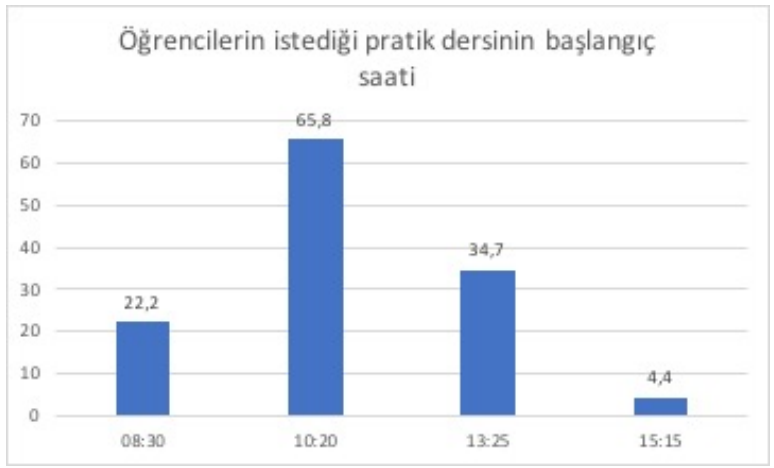

Şekil 1.

Öğrencilerin anatomi pratik derslerinin başlamasını istediği saatler

Tablo I'e baktığımızda, anatomi pratik derslerindeki en etkili öğrenme yöntemleri hakkında öğrenci düşünceleri belirtilmektedir. Bunun yanında, anatomik sistemler hakkındaki düşünceleri de değerlendirilmiştir. Buna göre, osteoloji ve nöroanatomi ders kurulları öğrencilerin en çok ilgi duyduğu kurullar olarak belirlenmiştir. Ancak nöroanatomi konularının öğrenilmesinde öğrencilerin zorluk yaşadıkları tespit edilmiştir (Tablo II).

Tablo I. Anatomi pratik uygulamalarının en iyi yöntemi sizce hangisidir?

\begin{tabular}{|l|c|}
\hline & ORAN (\%) \\
\hline Kitap ve atla yardımıyla kişisel çalışma & 35,8 \\
\hline Öğretim üyelerinden dinleyerek & 40,9 \\
\hline Arkadaşları ile birlikte çalışarak & 23,3 \\
\hline
\end{tabular}

Tablo II. Anatomi pratik uygulamalarında, anatomik sistemlerin değerlendirilmesi (n)

\begin{tabular}{|c|c|c|c|c|c|c|c|c|}
\hline \multirow[b]{2}{*}{ Sistemler } & \multicolumn{3}{|c|}{ Hareket } & \multirow[b]{2}{*}{ 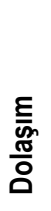 } & \multirow[b]{2}{*}{$\begin{array}{l}\text { ㅌ } \\
\text { D } \\
\text { 응 }\end{array}$} & \multirow[b]{2}{*}{ 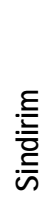 } & \multirow[b]{2}{*}{ 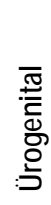 } & \multirow[b]{2}{*}{ 言 } \\
\hline & 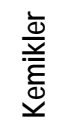 & $\frac{\frac{\bar{d}}{\bar{E}}}{\frac{\mathrm{d}}{\mathrm{L}}}$ & $\begin{array}{l}\frac{\bar{\pi}}{\mathscr{g}} \\
\check{\Xi}\end{array}$ & & & & & \\
\hline $\begin{array}{l}\text { En çok ilgi } \\
\text { duydukları }\end{array}$ & 98 & 22 & 44 & 37 & 18 & 30 & 25 & 53 \\
\hline $\begin{array}{l}\text { En iyi } \\
\text { öğrendikleri }\end{array}$ & 114 & 42 & 37 & 28 & 17 & 49 & 28 & 7 \\
\hline $\begin{array}{l}\text { En kötü } \\
\text { öğrendikleri }\end{array}$ & 51 & 75 & 39 & 12 & 13 & 7 & 10 & 51 \\
\hline
\end{tabular}

Çalışmamız sonucunda aldığımız yanıtlar değerlendirildiğinde, öğrencilerin \%83,4'ünün tıp fakültesi ter- 


\section{Anatomi Pratik Eğitim Değerlendirmesi}

cihlerini kendi istekleri yaptıkları ve bu öğrencilerin \%44,4'ünün Anadolu Lisesi mezunu oldukları ortaya konmuştur. Kendi isteği dişında tıp fakültesi tercihi yapan öğrencilerin \%45,7'sinin ise Fen Lisesi mezunu oldukları belirlenmiştir. Ancak mezun olunan lise ile tıp fakültesi tercihinin kendi isteği ile yapılıp yapılmaması arasında istatistiksel olarak anlamlı bir fark bulunmamıştır $(\mathrm{p}=0,58)$. Tıp fakültesini kendi isteği ile tercih edenlerin \%53,2'si ve kendi isteği ile tercih etmeyenlerin \%70,3'ünü erkekler meydana getirmektedir. Bununla birlikte, tıp fakültesi seçiminde öğrencinin isteği ile cinsiyet arasında istatistiksel olarak anlamlı bir fark bulunamamıştır $(\mathrm{p}=0,06)$.

Pratik sınavlarının nasıl yapılmasını istediklerini sorulduğunda, öğrencilerin $\% 74,8$ 'i maket ve kadavra üzerinde zilli sınav, \%14,6's1 slayt şeklinde ve \%10,2'si ise sözlü sınav istediklerini belirtirken, \%0,4'lük bir kesim bu soruya herhangi bir cevap vermemişlerdir. Pratik sınavın sözlü olarak yapılmasın1 isteyen öğrencilerin \%78,3'ü, kadavra ve maket üzerinde zilli sinav isteyenlerin \%49,7'si ve slayt sınav1 isteyenlerin \%66,7'si erkek öğrencilerden oluşmaktadır. Kadın ve erkek öğrenciler arasındaki sınav tipi sorusunun cevapları karşılaştırıldığında, kadavra ve maket üzerinde zilli sınav ile sözlü sınav isteyen öğrenciler arasında istatistiksel olarak anlamlı bir fark bulunmazken ( $\mathrm{p}=0,07)$, sözlü sınavı istemeleri cinsiyetler arasında karşılaştırıldıklarında, aradaki fark erkek öğrenciler lehine istatistiksel olarak anlamlı bulunmuştur $(\mathrm{p}=0,01)$. Bunun yanımda, anatomi pratik derslerinin öğretim üyelerinden dinlenerek daha başarılı olacağını söyleyen öğrencilerin \%53,4'ü, pratik derslerinde öğretim üyelerinin ders anlatılmas1nı yeterli olarak bulmuşlardır. Ayrıca, pratik derslerde, öğretim üyelerinin ders anlatma süreleri sorulduğunda, öğrencilerin verdikleri yanıtların ortalaması

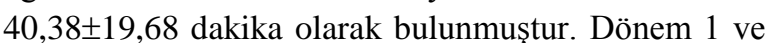
dönem 2 öğrencilerinin verdikleri yanıtlar karşılaşt1rıldığında, dönem 2 öğrencilerinin pratik derslerinde öğretim üyelerinin daha fazla ders anlatmalarını istemeleri istatistiksel olarak anlamlı bulunmuştur ( $\mathrm{p}<$ 0,001).

Anatomi pratik derslerinin değerlendirilmesi için, öğrencilerin "Evet”, "Hayır" ve "Kararsızım" şeklindeki kısa cevaplı sorulara verdikleri Tablo III'de gösterilmiştir. Buna göre, öğrencilerin $\% 47,1$ 'i ders programında yer alan anatomi pratik ders saatlerini yeterli olarak bulurken, \%30,9'u yetersiz bulmuştur. Öğrencilerin sadece \%9,8'i mezuniyet sonrası uzmanlık alanı olarak anatomiyi seçebileceğini belirtirken, \%57,3’ü anatomiyi uzmanlık alanı olarak seçmeyi düşünmemektedir.
Tablo III. Öğrencilerin anatomi pratik derslerini değerlendirmeleri (\%)

\begin{tabular}{|l|c|c|c|}
\hline & Evet & Karasızım & Hayır \\
\hline $\begin{array}{l}\text { Uygulama ders sayısı ve süresi } \\
\text { yeterli mi? }\end{array}$ & 47,1 & 22 & 30,9 \\
\hline $\begin{array}{l}\text { Uygulama derslere devamsızlık } \\
\text { yapmamak ders başarısı çin gerekli } \\
\text { midir? }\end{array}$ & 51,6 & 18,7 & 29,8 \\
\hline $\begin{array}{l}\text { Öğretim üyeleri ile uygulama dersle- } \\
\text { rinde rahatça iletişim kurabiliyorum }\end{array}$ & 74,4 & 16,6 & 9 \\
\hline $\begin{array}{l}\text { Uygulama dersinden konuyu anlamış } \\
\text { olarak çıkıyorum }\end{array}$ & 22,8 & 51,8 & 25,4 \\
\hline $\begin{array}{l}\text { Uygulama dersleri zaman kaybı } \\
\text { olarak görüyorum }\end{array}$ & 8,4 & 17,3 & 74,2 \\
\hline $\begin{array}{l}\text { Uygulama derslerindeki maketlerin } \\
\text { sayısı ve çeşitlilği yeterli mi? }\end{array}$ & 13 & 18,8 & 68,2 \\
\hline $\begin{array}{l}\text { Uygulama derslerindeki kadavra } \\
\text { sayısı yeterli mi? }\end{array}$ & 9,4 & 22 & 68,6 \\
\hline $\begin{array}{l}\text { Uygulama salonlarında radyolojik } \\
\text { görüntüler yardımcı ders aracı olarak } \\
\text { kullanılmalı mıdır? }\end{array}$ & 72,6 & 21,7 & 5,8 \\
\hline $\begin{array}{l}\text { Uygulama derslerinde gruptaki- } \\
\text { masadaki öğrenci sayısı öğrenme için } \\
\text { uygun mudur? }\end{array}$ & 25,3 & 24 & 50,7 \\
\hline $\begin{array}{l}\text { Uygulama derslerinin öğretim üyeleri } \\
\text { tarafından anlatıması öğrenmeyi } \\
\text { kolaylaştırıyor mu? }\end{array}$ & 87,4 & 8,6 & 4,1 \\
\hline $\begin{array}{l}\text { Uygulama dersi öncesi çalışma notu } \\
\text { verilmesi gereklimi? }\end{array}$ & 86,7 & 5,3 & 8 \\
\hline $\begin{array}{l}\text { Uygulama dersi öğrenimi konusunda } \\
\text { güçlük çekiyor musunuz? }\end{array}$ & 40 & 39,1 & 20,9 \\
\hline $\begin{array}{l}\text { Uygulama sonrasında sözlü sınav } \\
\text { yapımalı mı? }\end{array}$ & 12 & 14,7 & 73,3 \\
\hline $\begin{array}{l}\text { Uygulama dersi öncesinde öz hazırlık } \\
\text { yapıyor musunuz? }\end{array}$ & 39,1 & 32,4 & 28,4 \\
\hline $\begin{array}{l}\text { Kadavra diseksiyonu sırasında öğ- } \\
\text { renci katııımı olmasını ister misiniz? }\end{array}$ & 81,3 & 13,8 & 4,9 \\
\hline $\begin{array}{l}\text { Uzmanlık olarak anatomiyi seçer } \\
\text { miydiniz? }\end{array}$ & 9,8 & 32,9 & 57,3 \\
\hline $\begin{array}{l}\text { Seçmeli bir ders olarak anatomi } \\
\text { dersini alır mıydınız? }\end{array}$ & 47,6 & 22,7 & 29,8 \\
\hline
\end{tabular}

\section{Tartışma ve Sonuç}

Tıp eğitiminin eğitiminde önemli bir konuma sahip olan anatomi bilimi, görsel anlamda çok fazla miktarda detaya sahiptir. Yüzyıllardan bu yana süregelen, nasıl bir anatomi eğitimi sorusu, anatomi biliminin yeniliklere daima açık olduğunu ortaya koymaktadır. Bunun yanında, öğrenciler tarafından öğrenmekte ve kavramakta oldukça zorlanılan, ancak bunun aksine çok kolay unutulabilen bilgilere sahip olmasından dolayı anatomi eğitiminde kalıcılı̆̆ı arttırmayı hedefleyen yeni arayışlar içine girilmektedir. Bu noktada, anatomi eğitimi sırasında en çok güçlük çeken grup olan tıp fakültesi öğrencilerinin de görüşlerinin alınması, hoca - öğrenci iş birliği ile anatomi eğitiminin değerlendirilmesine yönelik çalışmalar bulunmaktadir ${ }^{6-8}$. 


\section{A. Vatansever, ark.}

Balıkesir Üniversitesi Tıp Fakültesinde 2017 - 2018 akademik yılında öğrenim dönem 1 ve dönem 2 öğrencilerinden oluşan toplam 226 öğrenciye, açık uçlu ve çoktan seçmeli olarak hazırlanan anket soruları yöneltilmiştir. Çalışmamız sonucunda, dönem 2 öğrencileri, pratik derslerde öğretim üyelerinin daha fazla süre ders anlatmasını isterken, çalışmaya katılan tüm öğrenciler arasında, ders programındaki anatomi pratik ders saatlerinin yeterli ya da yetersiz bulunması hakkında istatistiksel olarak anlamlı bir sonuç bulunamamıştır.

Yapılan bir çalışmada, anatomi derslerine devam etme zorunluluğunun, anatominin öğrenilmesi açısından önemli olduğunu düşünen öğrencilerin oranı \%79,6 iken, çalışmamız sonucunda devam gerekliliğinin öğrenim için gerekli olduğunu düşünen öğrenci oranı \%51,6 olarak tespit edilmiştir ${ }^{9}$. Yıllar içerisindeki bu düşmenin sebebini ortaya koymak için, daha geniş bir katılımcıya ulaşılarak detaylı bir cevap aranabilir.

Günümüzde teknolojinin önüne geçilemez hızdaki gelişmesi, sadece sanayi anlamında değil, aynı zamanda da eğitim alanında da heyecan verici yenilikler ortaya koymaktadır. Öğrencilerin, gelişen teknolojinin anatomi eğitimine dahil edilmesi ile ilgili görüşleri alındığında, cep telefonlarına, tabletlerine ve bilgisayarlarına kurabilecekleri anatomi eğitimi yazılımlarının anatomi eğitimine katkıları, öğrenciler tarafından olumlu olarak yorumlanmıştır ${ }^{10-12}$.

Sonuç olarak, sürekli işleyen ve yeniliklere açık bir süreç olan anatomi eğitiminin daha da ileriye taşınabilmesi için, öğrenci geri bildirimlerinin alınması, sadece anatomi için değil aynı zamanda çift taraflı etkileşimin de en önemli unsurlarından bir tanesidir. Tüm çalışmalardaki ortak sonuçlar göz önüne alınd1ğında, kalıcı, ilgi çekici ve etkileşimli bir anatomi eğitimi için teknolojinin tüm imkanlarından faydalanmanın da yadsınamaz etkisi gözler önüne konulmaktadır. Daha yaratıcı ve teknolojiden faydalanılarak uygulanan anatomi eğitiminin, daha kalıcı anatomi bilgisine sahip olan hekimlerin yetişmesinde ve uz- manlık olarak anatomi biliminin seçilme oranının arttırılabilmesinde etkili olabileceği düşünülmektedir.

\section{Kaynaklar}

1. Tuygar ŞF, Kuş İ, Saygılı ÖK, Özcan E, Gülcen B. Tıp fakültesi öğrencilerinin anatomi eğitimine yönelik memnuniyet düzeyleri ve ilgili değişkenlerin değerlendirilmesi. Tıp Eğitimi Dünyas1, 2015;42.

2. Taner D, (eds). Fonksiyonel anatomi: Ekstremiteler ve sirt bölgesi. 7. Baskı. Ankara: HYB Yayıncılık; 2013.

3. Yavuz F, Ertekin T, Elmalı F, Ülger H. Klinik öncesi ve klinik dönemde tıp öğrencilerinin anatomi eğitiminde kadavra kullanımı ile ilgili değerlendirmeleri. Erciyes Üniversitesi Sağlık Bilimleri Dergisi. 2017;26:227-32.

4. Carmichael SW, Pawlina W. Animated powerpoint as a tool to teach anatomy. Anatomical Record. 2000;26:83-8.

5. Hortsch M, Mangrulkar RS. When students struggle with gross anatomy and histology: a strategy for monitoring, reviewing, and promoting student academic success in an integrated preclinical medical curriculum. Anat Sci Educ 2015;8:478-83.

6. Özdemir ST, Cankur NŞ, Kurt MA. Tıp fakültesi öğrencilerinin anatomi uygulamaları hakkındaki görüşleri: Bir geri bildirim örneği. Uludağ Üniversitesi Tıp Fakültesi Dergisi. 2001;27(1):1 -8 .

7. Arı İ, İrgil E, Kafa İM, Şendemir E. Bir anket çalışması: Anatomi eğitimi ve öğrencilerin düşünceleri. Uludağ Üniversitesi Tıp Fakültesi Dergisi. 2003;29(2):15 - 8.

8. Arı İ, Şendemir E. Anatomi eğitimi üzerine öğrenci görüşleri. Uludağ Üniversitesi Tıp Fakültesi Dergisi. 2003;29(2):11 - 4.

9. Otağ İ, Otağ A. İnsan anatomisi ve fizyolojisi eğitimi üzerine öğrenci görüşleri. Cumhuriyet International Journal of Education. 2013;2(3):39 - 45.

10. Küçük S, Kapakin S, Göktaş Y. Tıp fakültesi öğrencilerinin mobil artırılmış gerçeklikle anatomi öğrenimine yönelik görüşleri. Yükseköğretim ve Bilim Dergisi. 2015;5(3):316 - 23.

11. Traser Cj, Hoffman LA, Seifert MF, Wilson AB. Investigating the use of quick response codes in the gross anatomy laboratory. Anatomical Science Education. 2015;8:421 - 8.

12. Khot Z, Quinlan K, Norman GR, Wainman B. The relative effectiveness of computer-based and traditional resources for education in anatomy. Anatomical Science Education. 2013;6:211 - 5 